\title{
RISK FACTORS ASSOCIATED WITH STROKE AFTER \\ TRANSCATHETER AORTIC-VALVE REPLACEMENT: ON THE WAY TO PREVENT IT
}

R. de Torres Chacon ${ }^{1}$, E. Ferrete Ruiz ${ }^{1}$, M.A. Gamero Garcia ${ }^{1}$, A. Dominguez Mayoral ${ }^{1}$, S. Perez Sanchez ${ }^{1}$, O. Araji Tiliani $^{2}$, M. Vizcaino Arellano 3 , J.M. Barquero Aroca ${ }^{2}$, J.A. Sanchez Miura ${ }^{1}$, L. Ruiz ${ }^{1}$, R. Ruiz Salmeron ${ }^{3}$, J. Montaner ${ }^{1}$ ${ }^{1}$ Neurology Department. ${ }^{2}$ Cardiovascular Surgery Unit and. ${ }^{3}$ Endovascular Unit, University Hospital Virgen Macarena, Seville, Spain.

\section{Introduction:}

Transcatheter aortic-valve replacement (TAVR) is a safe and effective option for severe aortic stenosis treatment. Stroke is one of its most important complications. We aimed to explore stroke incidence after TAVR in a real-life population and compare it with TAVR trials and also tried to identify predictive factors for stroke.

\section{Material and methods:}

TAVR patients from 2010-2016 performed by endovascular and cardiovascular surgeons were followed for one year. Baseline characteristics, stroke incidence and possible associated factors were recorded and compared to those in SURTAVI and PARTNER2 trials.

\section{Results:}

179 patients. Baseline characteristics of the whole cohort: $62 \%$ females, mean age 80 years, $83 \%$ were hypertensives, $47.5 \%$ diabetics and $51 \%$ had dyslipidemias. $40.8 \%$ had coronary disease and $35.8 \%$ atrial fibrillation (AF) before TAVR. At follow-up, new-onset AF was detected shortly following TAVR in $8.4 \%$ and $2.8 \%$ in the first year. Total incidence of stroke was $6.7 \%$ (12); 8 were ischemic, 3 hemorrhagic and 1 TIA. $75 \%$ of them occurred in late period, while only $25 \%$ in the first 30 days. No factors were associated with stroke appearance, except for a trend to have more strokes among those being hypertensive ( $82 \%$ vs $100 \%, p=0.1)$.
UNIVARIANT ANLYSIS IN PATIENTS WITH NEW STROKE FOLLOWING TAVR

\begin{tabular}{|c|c|c|c|}
\hline & NO & YES & p \\
\hline$N(\%)$ & $167(93.3 \%)$ & $12(6.7 \%)$ & \\
\hline 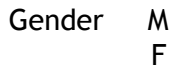 & $\begin{array}{c}63(37.7) \\
104(62.3)\end{array}$ & $\begin{array}{l}5(41.7) \\
7(58.3)\end{array}$ & 0.78 \\
\hline Age (median) & $80.2 \pm 6.9$ & $79.4 \pm 5.9$ & 0.53 \\
\hline HTA & $137(82)$ & $12(100)$ & 0.10 \\
\hline DM & 79 (47.3) & $6(50)$ & 0.85 \\
\hline DLP & 85 (50.9) & $6(50)$ & 0.95 \\
\hline FA & $61(36.5)$ & $3(25)$ & 0.42 \\
\hline Coronary D. & $67(40.1)$ & $6(50)$ & 0.50 \\
\hline 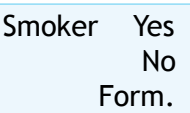 & $\begin{array}{c}6(3.6) \\
135(80.8) \\
9(5.4)\end{array}$ & $\begin{array}{c}0(0) \\
11(91.7) \\
0(0)\end{array}$ & 0.61 \\
\hline $\begin{array}{r}\text { Techniq End } \\
\text { Sur }\end{array}$ & $\begin{array}{l}141(84.4 \\
26(15.6)\end{array}$ & $\begin{array}{l}10(83.3) \\
2(16.7)\end{array}$ & 0.57 \\
\hline New onset FA & $19(11.4)$ & $1(8.3)$ & 0.74 \\
\hline
\end{tabular}

COMPARATION BETWEEN MAIN CLINICAL TRIALS AND OUR COHORT

\begin{tabular}{|c|c|c|c|c|}
\hline & $\begin{array}{l}\text { SURTAVI, } 2017 \\
\qquad(\mathrm{n}=879)\end{array}$ & $\begin{array}{c}\text { PARTNER 2, } 2016 \\
(n=1011)\end{array}$ & $\begin{array}{l}\text { Seville Cohort } \\
\quad(n=179)\end{array}$ & STROKE SUBTYPE $(\mathrm{N}=12)$ \\
\hline Age & 79.9 & 81.5 & 80 & $3 \%$ \\
\hline \multirow[t]{2}{*}{ Stroke incidence } & Early/Late & Early/Late & Early/Late & \\
\hline & $4.5 \% / 8.2 \%$ & $6.4 \% / 10.1 \%$ & $1.7 \% / 6.7 \%$ & \\
\hline Hypertension & $92.8 \%$ & -- & $83 \%$ & Hemorather \\
\hline Diabetes & $34.4 \%$ & $37.7 \%$ & $47.5 \%$ & Hemorrhagic \\
\hline Previous AF & $28.1 \%$ & $31 \%$ & $35.8 \%$ & \\
\hline New onset AF & - & $9.1 / 10.1 \%$ & $8.4 \% / 11.2 \%$ & \\
\hline
\end{tabular}

\section{Conclusion:}

In our sample, stroke incidence following TAVR is similar than in large clinical trials, despite the fact that real-life patients use to have higher vascular risk factors burden. Assessment by a Vascular Neurologist prior to procedure to control risk factors and optimize prevention could be the key to reduce post-TAVR stroke incidence. Biomarkers identification to predict high-stroke-risk profile would be desirable since there is a lack of stroke predictors in this population. 